\title{
Akats-korronteen mugaketa MMC bihurgailudun VSC-HVDC sistemetan
}

\author{
(Analysis and simulation of a FCL in a VSC-HVDC \\ system with MMC converters)
}

\author{
Araitz Iturregi*, Agurtzane Etxegarai, D. Marene Larruskain, \\ Pablo Eguia, Oihane Abarrategui \\ Bilboko Ingeniaritza Eskola. Euskal Herriko Unibertsitatea UPV/EHU \\ * araitz.iturregi@ehu.eus
}

DOI: $10.1387 /$ ekaia.16390

Jasoa: 2016-05-31

Onartua: 2016-09-26

Laburpena: Goi-tentsioko korronte zuzeneko (ingelesez, High Voltage Direct Current HVDC) garraio-sistemak gero eta garrantzitsuagoak dira sistema elektrikoan, onura ekonomiko eta teknikoak direla eta. Hala ere, akatsen bat gertatzen denean, korrontea eteteak oraindik ere erronka izaten jarraitzen du HVDC sareetan. Desiragarriak ez diren korronteak eteteko, korronte zuzeneko etengailuak erabil daitezke, baina horien gaitasuna mugatua da. Egoera hala izanik, akats-korronteen mugagailuak (ingelesez, Fault Current Limiter FCL) dira proposamenik egokiena akats-korronteak maneiagarriagoak diren balioetara txikitzeko; hartara, sistema elektrikoaren garraio-ahalmena handitu daiteke, ekipamendua aldatu beharrik gabe. Sarean aldez aurretik legokeen ekipamendua gai izango litzateke korronte berriak kudeatzeko eta sistema era eraginkorrean babesteko FCLen erabilpenaz. Artikulu honetan, FCL tresnen ezaugarri orokorrak eta sailkapena aurkezten dira. Ondoren, egoera solidoko FCLa erabili da maila anizkoitzeko bihurgailudun (ingelesez, Modular Multilevel Converter MMC) VSC-HVDC (ingelesez, Voltage Source Converter) sistema batean, eta horren jokaera azaltzen da simulazio bidez.

Hitz gakoak: Goi-tentsioko korronte zuzena (HVDC), akats-korronteen mugagailua (FCL), korronte zuzeneko etengailua, maila anitzeko bihurgailua (MMC), egoera solidoa, supereroaleak.

Abstract: High Voltage Direct Current (HVDC) transmission systems are playing an
important role due to their economical and technical benefits in the countries where the
electric grid is expanding fast. However, fault current interruption is still an unsolved
challenge in these HVDC grids. In order to interrupt undesirable currents, DC circuit
breakers can be used, but their capability is limited. Under that scenario, Fault Current
Limiters (FCL) arise as a good approach in order to reduce fault currents to a more 
manageable level allowing to increase the transmission ratings of an electrical system, without changing the equipment. Thus, the existing equipment would be able to handle the new currents and protect properly the system. In this paper, the general characteristics and classification of FCLs are explained. After that, a Solid State FCL is applied on a VSC-HVDC system with MMC converters. A simulation case of its optimal behavior is presented.

Keywords: HVDC, Fault Current Limiter, DC breaker, Modular Multilevel Converter (MMC), Solid State (SS), superconductors (SC).

\section{SARRERA}

VSC-HVDC teknologiak gorakada nabarmena izan du azken urteotan energiaren garraioan duen eraginkortasuna dela eta. Hamaika dira teknologia berri honetan nabarmendu daitezkeen abantailak, hala nola potentzia-galeren murrizketa, potentziaren erregulazio malguagoa edo konpentsaziorako beharrik eza. Hala ere, VSC-HVDC teknologiak sareko akatsen aurrean duen portaera oraindik ere luze aztertu eta jorratu beharreko gaia da. Akats-korronteak mugatzeak zailtasun handiak dakartza HVDC sistemetan, akats-korronteen balio altuak direla eta, eta korronte zuzenean korrontearen zero naturalik gertatzen ez delako. Hori dela eta, HVDC sistemen hedatzea mugatuta dago eta ikerketa-lan ugari korronte zuzeneko akatsen prebentziorantz bideratzen ari dira [1].

Korronte zuzeneko zirkuitu batean akatsa agertzean, akats hori lehenbailehen aurkitu eta desagerrarazi behar da, eragingo lituzkeen ondorioak leuntzeko. Akats-korronteak ezeztatzeko hainbat gailu daude, hala nola korronte zuzeneko etengailuak, korronte alternoko etengailuak edo akatsak blokeatzeko bihurgailuak. Baina, abiadurak eta etete-gaitasunak guztiz mugatzen ditu elementuok HVDC sistemetan lan egin ahal izateko. Beraz, beharrezkoa da beste aukera batzuk aztertzea, hala nola akats-korronteen mugatzea. Horrela, akats-korrontea deuseztatu beharrean, balio txikiagoetara mugatuko litzateke. Horretarako, beharrezkoa da zirkuituan korrontea mugatuko duen elementua sartzea, adibidez akats-korronteen mugagailua, ingelesez Fault Current Limiter (FCL) [2].

Korronteak mugatzeko metodoak metodo aktibo eta pasiboetan sailka daitezke (1. irudia).

Metodo pasiboak balio handiko inpedantzien erabilpenean oinarritzen dira, bai akats-egoeran bai egoera arruntean. Banandu eta mailakatu egiten dute sistema, horrek dakarren kostuarekin. Bestalde, zirkuitulaburreko inpedantzia altuko transformadoreak eta egoera arruntean sistemaren funtzionamendua aldatzen duten erreaktantziak ere erabil daitezke. 


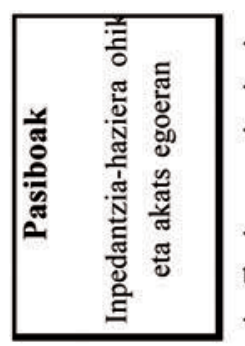

- Azpisareetan ba naketa

- Tentsio maila handitu

- Bus-banaketak

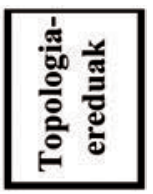

- Inpedantzia parasito altuko transformadoreak

- Haril korronte-mugatzaileak

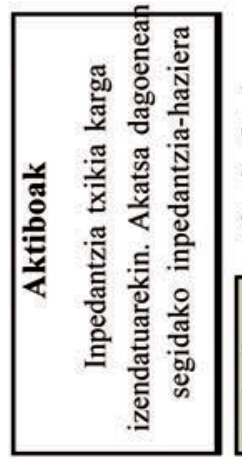

- Goi te ntsioko fusibleak

$(<1 \mathrm{kA},<36 \mathrm{kV})$

Is-mugagailuak

$(<4 \mathrm{kA},<36 \mathrm{kV})$

Te knologia a urre ratuak

Egoera solid oa

Supereroaleak

Sistema hibridoak

1. irudia. Korrontea mugatzeko aukerak korronte zuzeneko sareetan [3]

Korrontea mugatzeko metodo aktiboek, berriz, inpedantzia handitzea eragiten dute, baina akats-egoeretan bakarrik. Egoera arruntean, metodo aktiboek ez dute eraginik sarean; akats bat gertatzean, aldiz, korrontea mugatzen dute. Metodo aktiboak fusible, eta korronte-mugagailuetan oinarritzen dira. Horien artean Is-mugagailuak aurki ditzakegu. Is-mugagailuak fusible batez eta karga kimikoz osatutako korronte-mugagailuak dira. Jakina denez, fusibleek behin bakarrik lan egiteko gaitasuna dute akats-egoeran. Hortaz, erabilpen bakoitzaren ondoren ordezkatu behar dira, eta horrek desabantaila handia dakar. Is-mugagailuek ere fusibleen portaera berdina daukate, korrontea zirkuitulaburreko intentsitate-gandorra baino lehen mugatzen dutenean. Hartara, akats egoerako erabilpen bakoitzaren ostean hauek ere mantenua beharko dute.

Korronte-mugagailuak sailkatzeko beste era bat tresna-eredu eta topologia-ereduetan banatzea da (1. irudia). Eredu topologikoetan, korronte alternoko sistemetan gertatzen den moduan, beti banantzen da sarea eta, tamalez, potentziaren garraioa eteten da. Tresna-ereduetan oinarritutako korronte-mugagailuen artean egoera solidoko edo supereroaleko teknologiak erabiltzen dituzten FCLak dira etorkizunerako aukera gehien eskaintzen dutenak. 
Araitz Iturregi, Agurtzane Etxegarai, D. Marene Larruskain, Pablo Eguia, Oihane Abarrategui

Ondoko ataletan akats-korronteen mugagailu motarik garrantzitsuenak azalduko dira.

\section{AKATS-KORRONTEEN MUGAGAILUEN EZAUGARRI OROKORRAK}

Akats-korronteen mugagailuen helburua da sare elektrikoan akatsak gertatzen direnean korrontearen intentsitate-maila balio egokietara mugatzea. Gainera, operazio egonkorrean ez dute eragin nabarmenik izan behar. Hain zuzen, 2. irudian adierazten da mugagailuen operazio-printzipioa, ondoko parametro hauekin:

$-i_{\mathrm{n}}$ korronte izendatua

$-i_{\min }$ mugagailuak akatsa detektatzeko behar duen korronte minimoa

$-i_{\max }$ mugagailuak mugatutako korronte maximoa

$-t_{\mathrm{a}}$ operazio-denbora $t=0$ eta $i_{\max }$ arteko tartean

$-t_{\mathrm{d}}$ akatsaren iraupen-denbora

- $t_{\mathrm{r}}$ berreskuratze-denbora, korrontea eteten denetik FCLa hasierako egoerara bueltatu arte.

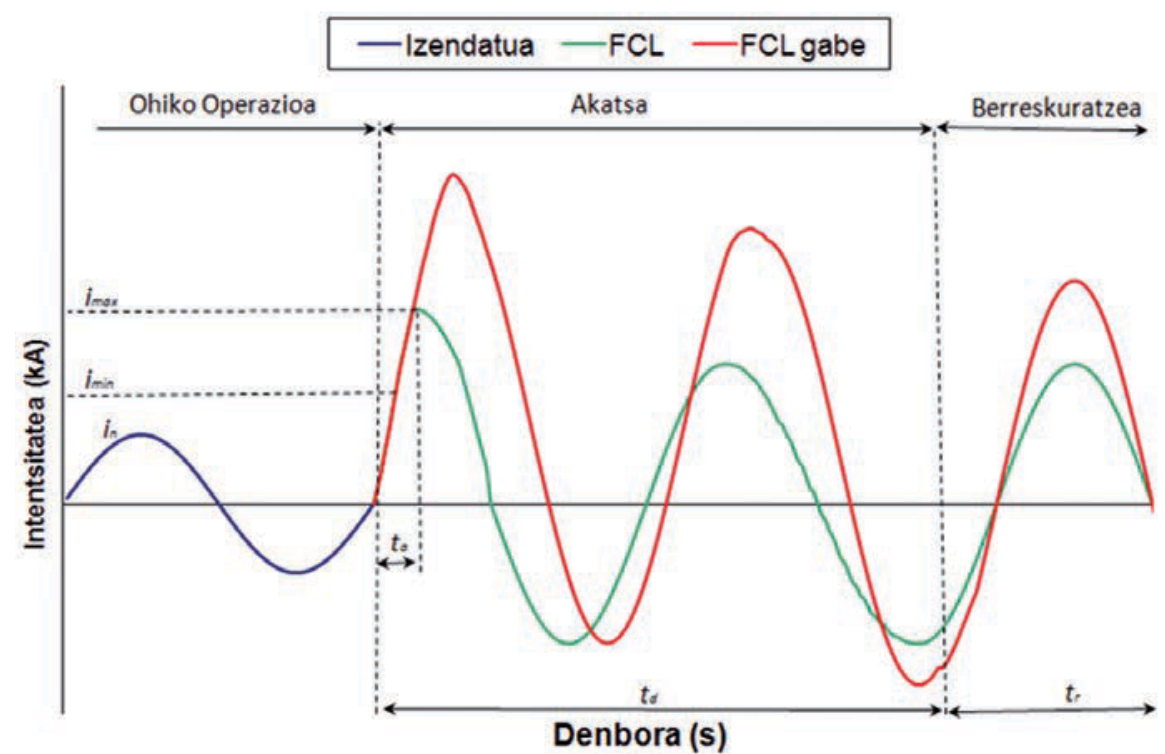

2. irudia. Akats-korronteen mugagailuaren operazio-printzipioa. 
FCL mugagailu idealek inpaktu minimoa izan behar dute operazio arruntean. Hau da, ez dute inpedantziarik agertu behar, tentsio-erorketak eta potentzia-galerak ekiditeko. Sarean akats elektrikoren bat gertatzean, ordea, mugagailuen inpedantzia handitu beharko litzateke, akats-korronteen intentsitate-maila mugatu ahal izateko. Bestalde, operazio azkarra beharrezkoa da, ahal izanez gero, korrontearen lehen zikloan, intentsitate-gandorra baino lehen. FCL idealek berehala berreskuratu behar dute hasierako egoera, eta ez lukete mantenurik behar eragiketa bakoitzaren ostean. Hala, gai izango dira operazio errepikatuak jasateko. Gainera, tresna eraginkorrak eta fidagarriak izan behar dira, tamaina konpaktukoak eta pisu arinekoak.

FCL tresna-eredu ugari proposatu dira. Hala ere, mugagailuen kontzeptua bera sakonago ikertu beharra dago, arestian aipaturiko ezaugarriak prezio baxura bateratzeko asmoz.

Hurrengo atalean, FCL tresnen mota nagusiak eta literaturan aurkitutako proposamenak aztertu eta sailkatuko ditugu.

\section{AKATS-KORRONTEEN MUGAGAILUEN TEKNOLOGIAK}

Akats-korronteen mugagailuak teknologia konbentzional eta teknologia aurreratuetan sailkatu ohi dira. Ohiko teknologiak honakoetan oinarritzen dira: azpiestazio berrien eraikuntzan, bus-banaketan, etengailuen hobekuntzan, erreaktantzia korronte-mugatzaileetan edota erresistentzia altuko lur-jartzeetan. Bestalde, teknologia aurreratuen artean, egoera solidoko mugagailuak (ingelesez, Solid State Fault Current Limiter, SSFCL) eta mugagailu supereroaleak (ingelesez, Superconducting Fault Current Limiter, SCFCL) aipa daitezke. Jarraian, teknologia aurreratuak aztertuko ditugu, eraginkortasun handiagoa eskaintzen dute eta.

\subsection{Egoera solidoko akats-korronteen mugagailuak}

SSFCLek potentzia-elektronika erabiltzen dute, sarean akatsik gertatuz gero zirkuituaren topologia aldatzeko. Berriki, nabarmen garatu dira potentziako gailu erdieroaleak, eta hortaz, aukerak zabaldu dira egoera solidoko mugagailuak hobetu eta komertzialki bideragarriak diren ereduak sortzeko. Mugagailu horien artean tiristore berrietan, IGBT motako transistore modernoetan eta silizioa baino errendimendu egokiagoa aurkezten duten material berrietan ( $\mathrm{SiC}$ gailuak kasurako [4]) oinarritutako tresnak aipa daitezke.

SSFCLen ezaugarri gisa honakoak aipa daitezke: operazio azkarra, berehalako berreskuratzea, operazio anizkoitzak jasateko ahalmena eta abio leunak (ingelesez, soft start). Hala ere, desabantaila nabariak dituzte, hala nola, eroapeneko galerak (ingelesez, on-state loss) eta kommutazioko galerak.

Ondoren, SSFCLen ohiko konfigurazioak aurkeztuko dira. 
Araitz Iturregi, Agurtzane Etxegarai, D. Marene Larruskain, Pablo Eguia, Oihane Abarrategui

\subsubsection{Txertatutako inpedantziadun egoera solidoko akats-korronteen mugagailuak}

Txertatutako inpedantziadun FCLek kommutagailu kontrolatu bat eta bypasseko hainbat adar dituzte (3. irudia). Kommutagailu kontrolatua noranzko bikoa izan ohi da eskuarki, eta gailu erdieroaleak antiparaleloan konektatuta daude. Kommutagailuak bypasseko adar korronte-mugatzaileetara desbideratzen du akats-korrontea edo zirkuitua irekitzen du, eta etengailu-funtzioa betetzen du.

Paraleloan dauden bypasseko adarrek elementu hauek dituzte: egoera egonkorreko bypass bat, korrontea mugatzeko gailu pasibo bat, gaintentsioen aurkako babesa (zink oxidozko baristorea, normalean), snubber zirkuitu indargetzaileak, eta beste hainbat elementu. Hala, SSFCLek diseinu sinpleak zein oso konplexuak izan ditzakete.

Txertatutako inpedantziadun SSFCLren zenbait ereduk linea isolatzeko kommutagailu bat izaten dute seriean konektatuta [5,6]. Diseinu horiek korrontea eteteko gai dira edozein atzerapen-denborarekin. Horrenbestean, FCLID (ingelesez, Fault Current Limiting and Interrupting Device) deritze. FCLIDen artean, diseinu batzuk korrontea eteteko gai dira soilik. Beraz, ez da beharrezkoa korrontea mugatzea. Beste diseinu batzuek, ordea, akatskorronteak mugatu ere egiten dituzte.

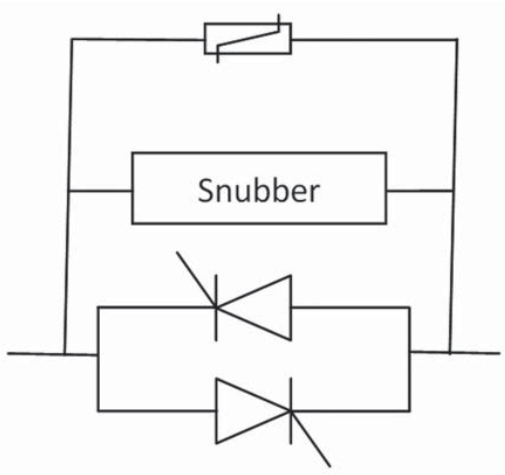

3. irudia. Txertatutako inpedantziadun mugagailua.

Txertatutako inpedantziadun FCLek egitura sinplea, erantzun azkarra eta performantzia ona izaten dituzte. Korronte zuzeneko aplikazioetarako aukera egokia izan daitezke. Adibidez, bihurgailuak detekzio-zirkuitu oso azkarrekin diseinatzen dira gaur egun. Hori dela eta, korronte zuzenerako hainbat proposamen aurki daitezke literaturan. Trakzio-aplikazioetan erabiltzeko, bi kommutazio-operaziodun etengailua aurkezten da [7] erre- 
ferentzian. Aldiz, Luo et al. autoreek kommutagailu nagusi konbinatudun FCLa proposatzen dute, IGBT (ingelesez, Insulated-Gate Bipolar Transistor) bakarra erabili ordez [8]. Azkenik, abiadura handiko etengailudun FCLa aurkezten da [9] erreferentzian.

\subsubsection{Egoera solidoko akats-korronteen mugagailu erresonanteak}

Egoera solidoko mugagailu erresonanteak operazio arruntean lineako maiztasunera zero balio inguruko serie-inpedantzia lortzeko doituta dauden serie-zirkuitu erresonanteetan oinarritzen dira [10]. Akatsik gertatuz gero, gailu elektronikoak berehala kommutatzen dira, eta zirkuituaren topologia aldatzen da. Gainera, erresonantziatik kanpo ateratzen dira, eta hortaz, zirkuitu berriaren inpedantzia altua izaten da. Hala, akats-korrontea mugatzen da.

LC motako zirkuitu erresonanteek hainbat konfigurazio aurkez ditzakete, elementuak seriean edo paraleloan konektatuz, 4. irudian adierazten den moduan. Hala ere, proposamen konplexuagoak ere aurki daitezke literaturan [10-12]. Oro har, FCL erresonanteak zirkuitu sinpleetan oinarritzen dira eskuarki, eta erraz inplementa daitezke. Kommutagailuak akats elektrikoak gertatzean aktibatzen dira, eta ondorioz, FCL hauetan galerak ez dira altuak. FCL erresonanteek errendimendu, fidagarritasun eta potentzia-kalitate ona izaten dute.

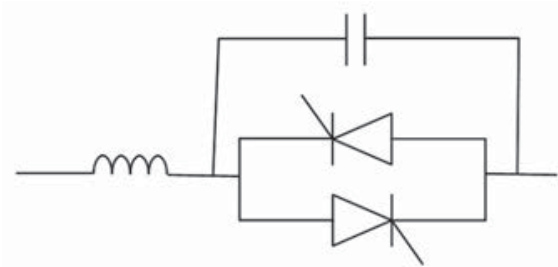

4. irudia. Egoera solidoko mugagailu erresonantea.

Desabantailetan artean, haatik, gaintentsioak, tentsio-hutsuneak eta erdieroaleetan eragindako korronte- edo tentsio-gainkargak aipa daitezke. Beharrezkoa den kapazitate-multzoaren tamaina eta kostua ere nabarmenak dira. Gainera, doitzeak eta detekzio-zirkuituak zehatzak izan behar dute. Funtzionamendua hobetzeko proposamenak aurkeztu dira, tentsio-erorketan oinarrituta, gehienetan [13].

\subsubsection{Zubi motako egoera solidoko akats-korronteen mugagailuak}

Zubi oso erdi-kontrolatu edo kontrolatuetan oinarritzen dira zubi motako egoera solidoko FCLak [14-16]. Egoera arrunteko bypassik ez da iza- 
ten, eta horrenbestez, baldintza normaletan, erdieroaleak aktibatuta daude. Akatsik gertatuz gero, erreaktantziak mugatzen du korrontearen intentsitatea. Diseinu berriak garatu dira fidagarritasun handiagoa eta portaera dinamiko hobea lortze aldera $[15,16]$.

Zubi motako FCLek tentsio-erorketa baxuak eragiten dituzte eta operazio anizkoitzak jasateko gai dira. Bestalde, mugagailu horiek tamaina handikoak eta garestiak izan ohi dira, akats-korronteen mugako balio altuak direla eta.

[1] erreferentzian zubi motako SSFCL baten diseinu sinplea aurkezten da, korronte zuzeneko garraio-sistema batean integratuz eta simulatuz.

\subsection{Akats-korronteen mugagailu supereroaleak}

Supereroankortasuna 1911n aurkitu zen. Hasiera batean, helio likidoaren tenperatura inguruan $(4 \mathrm{~K})$ operatzen zuten materialak erabili ziren. Ordea, 1986an, tenperatura altuko supereroaleak (High Temperature Superconductors, HTS) aurkitu ziren eta gertaera hori mugarri izan da geroztik ikertu diren akats-korronteen mugagailuen garapenean. Izan ere, HTS materialen operazio-tenperatura aurretiko materialena baino nabarmen altuagoa da, nitrogeno likidoaren tenperaturari dagokionaren ingurukoa. Ondorioz, zailtasun teknikoak eta kostua ere baxuagoak dira.

Bestalde, HTS materialak interesgarriak gerta daitezke energia-sistema elektrikoetan aplikatzeko. Hala, akats-korronteak mugatzeko ezaugarri egokiak dituzte; hala nola, akats-korronteen intentsitatea faktore altuarekin txikiagotzen dute, zenbait ziklotan desarra bakarra eragiteko gai dira, eta automatikoki berrezartzen dira. Baina, hala eta guztiz, gailuak hoztu eta akats aurreko tenperatura lortzeko zenbait minutu izaten dira beharrezko. Gainera, egoera egonkorrean Joule efektuaren ondoriozko galerarik egon ez arren, kontuan izan behar dira hozte prozesuko galerak.

Hainbat material supereroale erabili izan dira akats-korronteen mugagailu supereroale (SCFCL) gisa. Hain zuzen, 1. taulak adierazgarrienak aurkezten ditu.

Supereroankortasuna are egokiago izan daiteke korronte zuzeneko sistemetarako korronte alternokoetarako baino. Izan ere, material supereroaleak eremu magnetiko birakariekiko sentikorrak dira. Hala, xingola supereroaleen barneko eremu magnetikoaren banaketak korronte alternoko histeresiaren ondoriozko galerak eragin ditzake [18].

Honako atalean, tentsio altuko korronte zuzeneko HVDC sistemetan aplika daitezkeen SCFCL diseinuak azaltzen dira, literaturan aurkeztutako proposamenetan oinarrituta. 
1. taula. HTS materialak [17].

\begin{tabular}{cc|l}
\hline Materiala & $\begin{array}{c}\text { Tenperatura } \\
\text { kritikoak }\end{array}$ & \multicolumn{1}{c}{ Ezaugarriak } \\
\hline BSCCO & $110 \mathrm{~K}$ & Lehen belaunaldiko materiala. \\
\hline YBCO & $90 \mathrm{~K}$ & $\begin{array}{l}\text { Korronte kritiko altuak harilaren erradioarekiko. } \\
\text { Egonkortasun mekanikoa. }\end{array}$ \\
\hline $\mathrm{MgB}_{2}$ & $39 \mathrm{~K}$ & $\begin{array}{l}\text { Kostu baxua. } \\
\text { Trinkotasun mekanikoa. }\end{array}$ \\
\hline
\end{tabular}

\subsubsection{Akats-korronteen mugagailu supereroale erresistiboak}

SCFCL erresistiboak seriean konektatzen dira babestu beharreko linearekin (5. irudia). Mugagailu supereroale sinpleenak, konpaktuenak eta merkeenak dira.

Operazio arruntean, inpedantzia ia nulua dute. Baina korronteak, operazio-tenperaturak edota kanpoko eremu magnetikoak atalase jakin batzuk gainditzen dituztenean, supereroaleen inpedantzia hazi egiten da. Ondoren, akatsa desagertzean, beharrezko izaten dute supereroaleek hozteko denbora-tarte bat, segundo batzuetatik minutuak arte luza daitekeena. Berreskuratze-denbora material supereroalearen araberakoa da.

Hainbat erreferentziatan landu da SCFCL erresistiboen aplikazioa DC sistemetan [1, 17, 19-22], itsasontzietako energia-sistema elektrikoak barne [23].

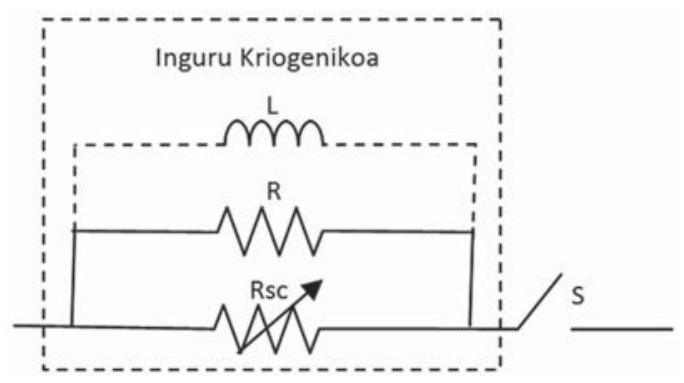

5. irudia. SCFCL erresistiboa.

\subsubsection{Egoera solidoko akats-korronteen mugagailu supereroaleak}

Egoera solidoko SCFCLei mugagailu hibrido ere baderitzegu, material erdieroaleak eta supereroaleak konbinatzen baitituzte. Egoera solidoko mugagailu supereroaleak bi taldetan sailka daitezke: zubi motakoak eta akatskorronteen kontrolagailuak. 
Zubi motako SCFCLek SSFCLen antzerako diseinua dute, baina induktantzia arrunta induktantzia supereroale batez ordezkatuz (6. irudia). Sakon ikertu da zubi motako SCFCLen inguruan, eta ondorioz, arrakastaz saiatutako zenbait diseinu aurki daitezke literaturan [24, 25]. Txinako Hunan eskualdean, azpiestazio erreal batean probatutako mugagailuaren kasua ere deskribatu da [26].

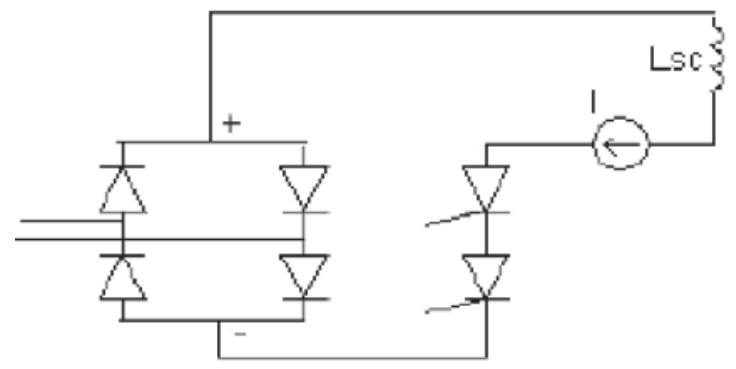

6. irudia. Zubi motako SCFCLa.

Bestalde, akats-korronteen kontrolagailu motako mugagailuak seriean konektatutako bi tiristore eta kommutagailu batez osatuta daude (7. irudia).

Gainera, tiristore bakoitza haril supereroale batekin konektatuta dago paraleloan. Zenbait prototipo eraiki dituzte, eta garapen-maila ezberdinak lortu dute $[27,28]$. Hala ere, tenperatura beroari eta tresneria kriogenikoari lotutako arazoak agertu dira probetan zehar.

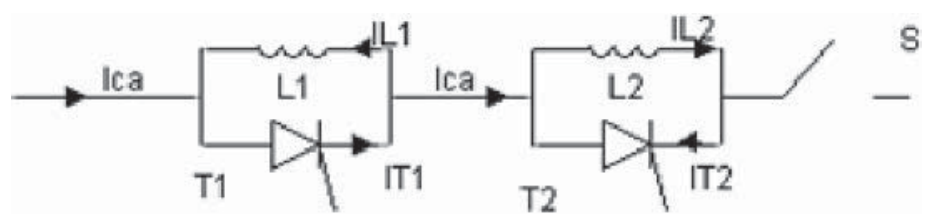

7. irudia. SCFCL korronte-kontrolagailua.

\subsubsection{Burdinazko nukleo korazaduneko akats-korronteen mugagailu supereroaleak}

Mugagailu horietan harilkatu primarioa ohikoa da eta kulatadun burdinazko nukleo baten inguruan biribilkatuta dago. Erdian zilindro supereroale bat dago kokatuta. Sekundarioa material supereroalearekin itxita duten transformadoreekin aldera daitezke mugagailu horiek. Akatsa gertatzean, harilkatu sekundarioko korrontearen intentsitaterik altuenek supereroalearen iraungipena eragiten dute, eta tentsioa igotzen da. 
Nukleo korazaduneko SCFCLak DC sistemetan erabili ahalko lirateke, baina beste mugagailu mota batzuk baino tamaina handiagoa daukate eta lehiakortasun txikiagoa [1]. Tamalez, gailu induktiboek sarean metatutako energia handitzen dute akatsak irauten duen bitartean. Hori dela eta, korronte zuzeneko etengailuetan zailagoa da energia xahutzea, eta akats ostean, gaintentsio altuagoak sor daitezke.

\subsubsection{DC polarizaziodun burdinazko nukleoko akats-korronteen mugagailu supereroaleak}

DC polarizaziodun burdinazko nukleoko mugagailuei nukleo aseko mugagailuak ere esaten zaie. Polarizazio magnetikoa eragiten duten korronte konstanteko harilkatu supereroaledun bi burdinazko nukleoz osatuta daude (8. irudia). Ohiko egoeran, lineako korrontea baxua izan ohi da, eta nukleoak ase egiten dira DC korronte polarizatuak direla eta. Beraz, ohiko operazio-puntua zonalde asean dago mugagailu hauentzat. Asetasun egoeran, burdinaren iragazkortasun erlatiboa unitatearen ingurukoa denez, korronte alternoko harilentzat burdinak aireak bezala jokatzen du. Beraz, induktantziak oso txikiak dira.

Akatsa gertatzean, lineako korronte alternoaren intentsitateak asetasun egoeratik ateratzen ditu harilak, eta iragazkortasun handiko funtzionamendu-zonaldera bultzatu. Hortaz, guztizko induktantzia handitu egiten da. Hala, mugagailu hauetan ez da supereroalearen egoera-aldaketarik gertatzen. Beraz, akats ostean ez dago berreskuratze-tarterik. Hori dela eta, sistema kriogeniko txikiak erabiltzen dira.

DC polarizaziodun burdinazko nukleoko mugagailuak proposatu ziren hasiera batean tenperatura baxuko supereroaleentzat (Low temperature Superconductor, LTS) [29]. Horregatik, beharrezko sistema kriogenikoak tamaina handikoak eta garestiak ziren. Jatorrizko diseinua hainbat ikerlanetan hobetu dute [30]. HVDC sistemetarako ere proposatu da kontzeptu bera $[1,22]$.

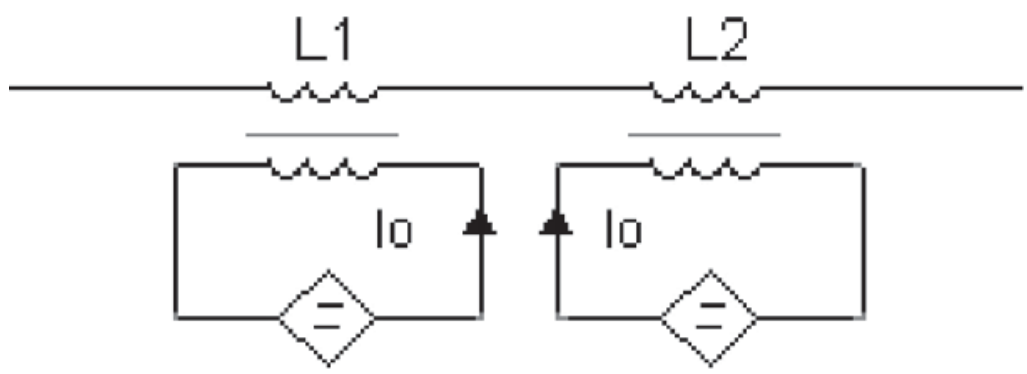

8. irudia. DC polarizaziodun burdinazko nukleoko SCFCLa. 
Araitz Iturregi, Agurtzane Etxegarai, D. Marene Larruskain, Pablo Eguia, Oihane Abarrategui

\subsection{Konparaketa}

Aurretik ikusitako korronte-mugagailu guztiak laburbiltzeko asmoz, 2. taula aurkezten da honako atalean.

2. taula. Akats-mugagailuen konparaketa

\begin{tabular}{|c|c|c|c|c|c|}
\hline \multicolumn{3}{|c|}{ Mugagailu mota } & Tamaina & Berreskuratzea & $\begin{array}{c}\text { DCrako } \\
\text { egokia }\end{array}$ \\
\hline \multirow{3}{*}{ 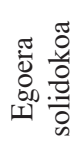 } & \multicolumn{2}{|c|}{ Txertaturiko inpendantzia } & Ertaina-Txikia & Berehalakoa & Bai \\
\hline & \multicolumn{2}{|c|}{ Erresonantea } & Ertaina-Txikia & Berehalakoa & Ez \\
\hline & \multicolumn{2}{|c|}{ Zubi motakoa } & Ertaina & Berehalakoa & Bai \\
\hline \multirow{5}{*}{ 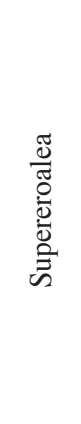 } & \multicolumn{2}{|c|}{ Erresistiboa } & Txikia & Segundoak-Minutuak & Bai \\
\hline & \multicolumn{2}{|c|}{ Burdinazko nukleo korazaduna } & Handia & Segundoak & $\mathrm{Ez}$ \\
\hline & \multirow{2}{*}{$\begin{array}{l}\text { Egoera } \\
\text { solidokoa }\end{array}$} & Zubi motakoa & $\begin{array}{l}\text { Ertaina- } \\
\text { Txikia }\end{array}$ & Segundoak-Minutuak & Bai \\
\hline & & $\begin{array}{c}\text { Akats-korronteen } \\
\text { kontrolagailu } \\
\text { motakoa }\end{array}$ & Ertaina & Berehalakoa & Bai \\
\hline & \multicolumn{2}{|c|}{ DC polarizaziodun burdinazkoa } & $\begin{array}{l}\text { Ertaina- } \\
\text { Handia }\end{array}$ & Berehalakoa & Bai \\
\hline
\end{tabular}

Taula honetan, akats-mugagailuen ezaugarri garrantzitsuak laburbildu dira, hala nola, bakoitzaren tamaina eta berreskuratze-denbora. Tamaina erabakigarria izango da mugagailuaren aplikazioa zehazteko orduan, eta berreskuratze-denborak, berriz, mugagailuak operazio anitzak izan ditzakeen erabakiko du. Bestalde, mugagailuak korronte zuzeneko aplikazioetarako egokiak diren adierazten da kasu bakoitzerako, aurreko ataletan aipatutako aplikazioetan oinarrituz. Hala, egoera solidoko mugagailuen artean, txertaturiko inpedantziadunak edo zubi motakoak dira korronte zuzeneko aplikazioetarako egokiak, baina ez erresonanteak. Mugagailu supereroaleen artean ostera, erresistiboak, DC polarizaziodun burdinazkoa edo egoera solidokoak dira DCko aplikazioentzako egokiak.

\section{IKASKETA-KASUA}

Atal honetan ikasketa-kasu bat aurkezten da, eta HVDC sistema batean FCL baten funtzionamendua azaltzen da. Simulazioa PSCAD softwarearen bidez egin da, eta korronte zuzeneko sare gisa CIGRE B4.57 lantaldeak 
sortutako sistema erabili da. Lantalde horrek HVDC sareetako bihurgailuen ereduak garatzeko gida zabaldu du [31]. Dokumentuan hiru kasu deskribatzen dira: DCS1 sisteman puntuz puntuko HVDC lotura, DCS2 sisteman 4 terminal dituen korronte zuzeneko sarea, eta azkenik, DCS3 sisteman, aurreko bi kasuak biltzen dituen 9 terminaleko sistema bipolarra. Artikulu honetan aurkezten den ikasketa-kasua DCS1 test-sisteman oinarritzen da (9. irudia).

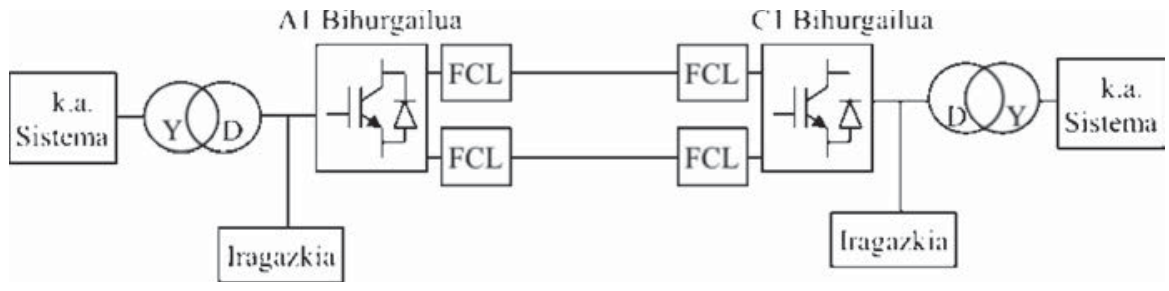

9. irudia. Bi terminal dituen puntuz puntuko sistema [31].

Bi terminaldun HVDC lotura polobakar simetrikoa azaltzen da 9. irudian. Bertan dagoena da $\mathrm{C} 1$, itsas zabaleko haize-parkeari dagokion bihurgailua, eta $\mathrm{A} 1$, lur barneko terminalari dagokion bihurgailua. A1 eta $\mathrm{C} 1$ 200 km-ko luzera duen XLPE kable baten bidez konektatzen dira. Bihurgailuen parametrorik garrantzitsuenak adierazten dira 3. taulan.

3. taula. Bihurgailuen ezaugarriak.

\begin{tabular}{cccc}
\hline Bihurgailua & Potentzia izendatua (MV A) & K.Z. tentsioa $(\mathrm{kV})$ & Operazio-moduaren hasiera \\
\hline A1 & 800 & $+/-200$ & $Q=0, V_{\mathrm{DC}}=1$ p.u. \\
C1 & 800 & $+/-200$ & $P=500 \mathrm{MW}, Q=0$ Mvar \\
\hline
\end{tabular}

A1 eta C1 MMC motako bihurgailuak dira. Gaur egun, teknologia hau arrunta da. Bestalde, DC kondentsadoreak kizkurdura \% 10ekoa baino txikiago izateko aukeratu dira. Bihurgailuen galerei dagokienez, kommutaziogalerak baztertu egin dira, eta eroapeneko galerak potentzia izendatuaren $\%$ lekoak dira.

Ikasketa-kasua DCS1 sistemaren korronte zuzeneko sarean oinarrituta dagoenez, sinplifikatu egin dira korronte alternoko iturriak. Hortaz, korronte alternoko sareak tentsio-iturri erreal modura modelizatu dira. A1 terminalaren korronte alternoko aldean $380 \mathrm{kV}$-eko tentsio konposatua dago eta C1 terminalean, aldiz, $145 \mathrm{kV}$-ekoa. Sareko zirkuitulaburreko potentzia $30 \mathrm{GV}$ A da, $R / X$ ratioa 0,1 izanik. 

Oihane Abarrategui

Txertatutako inpedantziadun egoera solidoko FCL bat instalatu da A1 eta $\mathrm{C} 1$ bihurgailuen polo positiboen eta negatiboen artean. Ikasketa-kasua C1 bihurgailuaren DC busean 1,0 s unean agertzen den poloen arteko akats iraunkorra da, 10. irudian adierazten den moduan. Akatsaren erresistentzia $0,01 \Omega$ da. Irudian A1 eta $\mathrm{C} 1$ bihurgailuen korronte zuzeneko intentsitateak alderatzen dira, FCLarekin (hurrenez hurren, linea morea eta urdina), eta FCLrik gabe (hurrenez hurren, linea gorria eta berdea). Akatsa agertzen denean, korronte zuzeneko loturan, detektagailuak mikrosegundo gutxitan detektatzen du akatsa, eta FCLak behar bezala funtzionatzen du. Akats-korronte altua murriztu egiten du operazio azkar baten bidez.

Akats bat gertatzen denean, hainbat urrats ematen dira, 10. irudian ikusten den moduan.

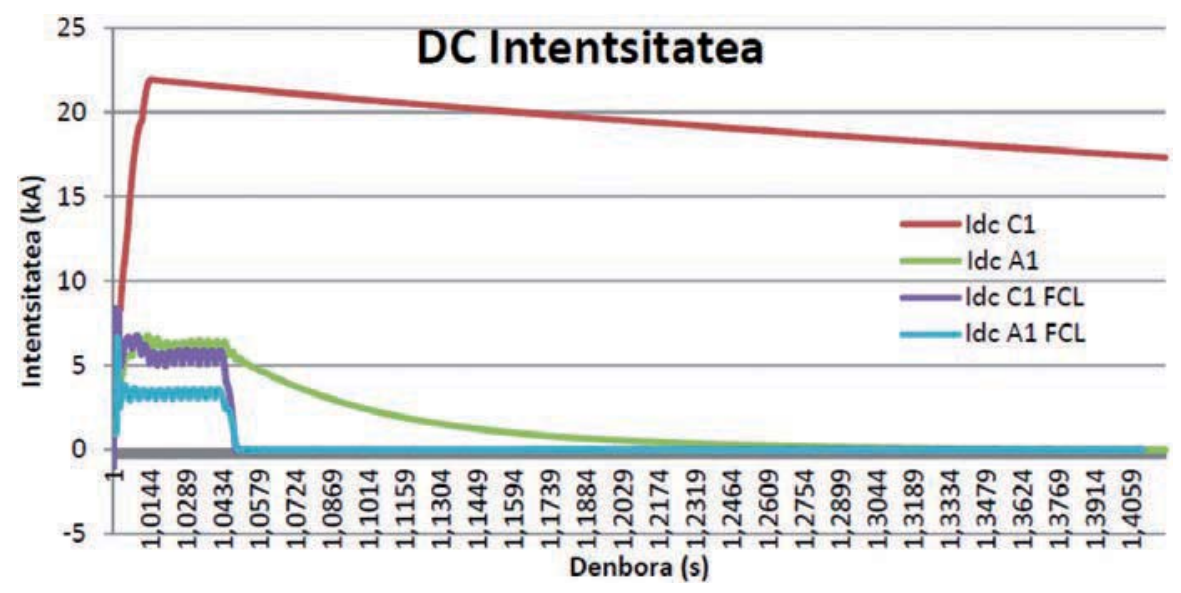

10. irudia. Akats-korronteak. Bihurgailuen korronte zuzeneko intentsitatearen alderaketa (kA) FCLrekin eta FCLrik gabe.

Hasierako urratsean, intentsitatea bat-batean handitzen da, bihurgailuetako kondentsadoreak deskargatzen direlako. $\mathrm{C} 1$ bihurgailuan akatskorrontearen gandorreko intentsitatea $8,7 \mathrm{kA}$ da, eta korronte-gradientea, aldiz, 13,9 kA/ms. A1 bihurgailuan intentsitatea 6,18 kA-ra iristen da $5,5 \mathrm{~ms}$-an. Uhin bidaiariaren transmisio-denboragatik atzerapena sortzen da kablean zehar. Hortaz, korronte-gradientea $1,3 \mathrm{kA} / \mathrm{ms}$-ra murrizten da. Hasierako urrats horretan, FCLak ez du eraginik. C1 eta A1 bihurgailuek blokeatu egiten dituzte sortutako gainintentsitateak.

Bigarren urratsa ezberdina da bi kasuetan. FCLrik gabeko kasuan, korrontea areago handitzen da, korronte alternoko sistemak emandako intentsitateagatik. FCLa erabiliz gero, bihurgailuaren balbulak blokeatzean aktibatzen da. Hala, mugagailuak adar nagusiaren zirkuitua irekitzen du, eta 
korrontea adar paralelotik bideratzen du. Bertan, baristoreak akats-korrontearen intentsitatea 7,9 kA-ra mugatzen du. Beraz, korronte zuzeneko intentsitatea mugatzen da, FCLrik gabeko kasuan 21,9 kA baita. Mugatutako intentsitatea baristorearen bidez alda daiteke, eta, beharrezkoa balitz, mugatutako intentsitatea txikiagoa izan ahalko litzateke.

Ondoren, $\mathrm{C} 1$ bihurgailuaren korronte alternoko aldean dagoen etengailu automatikoak desarratu egiten du eta geroago, A1 bihurgailuaren etengailuak. Hortaz, Clen eta Alen intentsitateak elkarren segidan nulu egiten dira.

FCLak behar bezala lan egin duela agertzen da 11. irudian, eta operazio-denbora oso arina da. FCLen eskaririk garrantzitsuenen artean dagoen ezaugarria da hori.

C1 bihurgailuaren korronte zuzeneko tentsioa akatsagatik bat-batean anulatu egiten da, 11. irudian adierazten den moduan. A1 bihurgailuak korronte zuzeneko tentsioa kontrolatzen du, eta tentsioa 0,5 batekotan $(0,5 \mathrm{pu})$ mantentzen du zenbait milisegundo. Azkenik, tentsioak oszilazio indargetuak jasaten ditu, eta nulu egiten da akatsa sortu baino $75 \mathrm{~ms}$ beranduago. Funtzionamendua FCLrik gabeko kasuan deskribatutakoaren antzerakoa da.

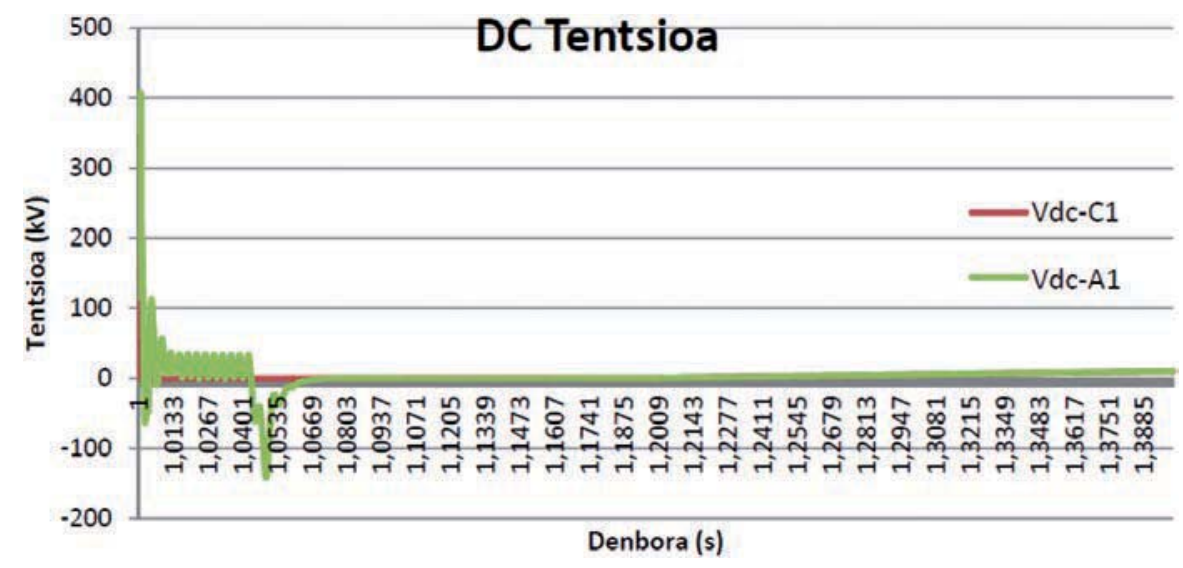

11. irudia. Bihurgailu bakoitzaren korronte zuzeneko tentsioa $(\mathrm{kV})$.

Erregimen iraunkorrean, $\mathrm{C} 1$ bihurgailuak artezgailu moduan lan egiten du; A1 bihurgailuak, aldiz, inbertsore gisa. Hau da, ohiko egoeran korronte zuzeneko potentzia-fluxua haize-parkeko $\mathrm{C} 1$ bihurgailutik lurrean dagoen A1 bihurgailura doa. Akatsa dela eta, $\mathrm{C} 1$ bihurgailuaren potentzia segidan anulatzen da, tentsioa erortzen delako, eta A1 bihurgailua artezgailu moduan lan egitera pasatzen da. Beraz, korronte alternoko sistemak akatsa eli- 
Araitz Iturregi, Agurtzane Etxegarai, D. Marene Larruskain, Pablo Eguia, Oihane Abarrategui

katzen du 50 ms-an. Ondoren, etengailuak desarratzen duenean, potentzia anulatu egiten da.

\section{ONDORIOAK}

HVDC sareen babesa erabakigarria izango da etorkizunean. Gaur egun, korronte zuzeneko etengailuak ez dira eraginkorrak, akats-korronteen intentsitateak altuak direlako eta korrontea zerotik igarotzen ez delako. Artikulu honetan FCL tresnen teknologiarik berrienak azaldu dira, eta akats-korronteak mugatzeko duten gaitasuna aztertu da. Hala, FCL mugagailuen operazioa eta ezaugarriak zerrendatu dira, eta DC sistemetarako tresnarik egokienak nabarmendu dira. HVDC sareetan, hortaz, txertatutako inpedantziadun egoera solidoko akats-korronteen mugagailuak, akats-korronteen mugagailu supereroale erresistiboak eta DC polarizaziodun burdinazko nukleoko akats-korronteen mugagailu supereroaleak dira egokienak.

Tamalez, FCL mugagailuak garapen bidean daude, teknikoki eta ekonomikoki agertutako zailtasunak direla medio. Azken urteotan, egoera solidoko mugagailuek eta teknologia supereroaleek bultzada handia jaso dute. Adibide baterako, izugarri garatu dira HTS motako materialak eta gailu erdieroaleak. Hortaz, uste izatekoa da teknologiak aurrera egiten badu eta prezioak murrizten badira, etorkizun hurbilean FCLen erabilera zabalduko dela. Etorkizuneko korronte zuzeneko sareen garapenerako aukera aproposa eskaintzen da, beraz.

FCL mugagailuen artean, egoera solidoko mugagailu baten aplikazioa aztertu da artikulu honetan, bi terminaldun VSC-HVDC sistema batean. Sistema eta FCLa modelizatu ondoren, akats bat sortu da simulazio bidez. Hala, mugagailuaren portaera aztertu da, operazio arruntean eta akatsa sortutako unean. Simulazioaren emaitzen arabera, egoera solidoko mugagailuak akats-korrontea mugatzeko gaitasun egokia agertu du, eta erantzuna azkarra eta egokia izan da.

\section{ESKER ONAK}

Artikulu honek UPV/EHUk finantzatutako EHUA15/25, Eusko Jaurlaritzak finantzatutako ELKARTEK 2015 HVDCLINK eta Estatuko Ikerketa Agentziak eta Eskualde Garapenerako Europar Funtsak ENE2016-79145-R (AEI/FEDER, UE) proiektuen baitan garatutako lana aurkezten du.

Bestalde, eskerrak luzatu nahi dizkiogu Euskal Filologia Saileko Jose Ramon Etxebarriari, testua hizkuntza aldetik berrikusten laguntzeagatik eta erakutsitako guztiagatik. 


\section{BIBLIOGRAFIA}

[1] S. ECKROAD, «Superconducting Fault Current Limiters», EPRI Technical Update 1017793, pp. 68, 2009.

[2] CIGRE WG A3.10, «Fault Current Limiters», 2006.

[3] STEURER, M. and FRÖHLICH, K., «Current limiters- state of the art», in Fourth Workshop \& Conference on EHV Technology, Bangalore, India, 1998, pp. 1-7.

[4] Z.C. FENG, SiC Power Materials. Devices and Applications. Germany: Springer, 2004.

[5] G.A. PUTRUS, N. JENKINS and C.B. COOPER, «A static fault current limiting and interrupting device», in Fault Current Limiters - A Look at Tomorrow, IEE Colloquium on, 1995, pp. 1-6.

[6] S. SUGIMOTO, Y. KIDA, H. ARITA, C. FUKUI and T. YAMAGIWA, «Principle and characteristics of a fault current limiter with series compensation», Power Delivery, IEEE Transactions on, vol. 11, pp. 842-847, 1996.

[7] P.M. McEWAN and S.B. TENNAKOON, «A two-stage DC thyristor circuit breaker», Power Electronics, IEEE Transactions on, vol. 12, pp. 597-607, 1997.

[8] F. LUO et al., «A novel solid state fault current limiter for DC power distribution network», in Applied Power Electronics Conference and Exposition, 2008. APEC 2008. Twenty-Third Annual IEEE, 2008, pp. 1284-1289.

[9] L. LIU, J. ZHUANG, C. WANG, Z. JIANG, J. WU and B. CHEN, «A Hybrid DC Vacuum Circuit Breaker for Medium Voltage: Principle and First Measurements», Power Delivery, IEEE Transactions on, vol. 30, pp. 20962101, 2015.

[10] G.G. KARADY. Principles of fault current limitation by a resonant LC circuit. Generation, Transmission and Distribution, IEE Proceedings C 139(1), pp. 1-6. 1992.

[11] PENG. C., «Potential use of fault current limiter in VSC based DC transmission systems», in Power and Energy Engineering Conference (APPEEC), 2012 Asia-Pacific, 2012, pp. 1-4.

[12] M. LANES, H. BRAGA and P. BARBOS, «Limitador de Corrente de CurtoCircuito Baseado em Circuito Resonante Controlado por Dispositivos Semicondutores de Potência», IEEE Latin America Transactions, vol. 5, pp. 311$320,2007$.

[13] S.B. NADERI, M. JAFARI and M. TARAFDAR HAGH, «Parallel-Resonance-Type Fault Current Limiter», Industrial Electronics, IEEE Transactions on, vol. 60, pp. 2538-2546, 2013.

[14] W. ZHAO-LIN, C. PING-PING, T. LING-YUN and J. DAO-ZHUO, «Short circuit current limiter in as network», Journal of Zhejiang University Science, vol. 2, pp. 41-45, 2001.

[15] LU, Z.; JIANG, D. and WU, Z., «A new topology of fault-current limiter and its parameters optimization», in Power Electronics Specialist Conference, 2003. PESC '03. 2003 IEEE 34th Annual, 2003, pp. 462-465 vol. 1. 
Araitz Iturregi, Agurtzane Etxegarai, D. Marene Larruskain, Pablo Eguia, Oihane Abarrategui

[16] FEI, W. and ZHANG, Y., «A novel IGCT-based half-controlled bridge type fault current limiter», in Power Electronics and Motion Control Conference, 2006. IPEMC 2006. CES/IEEE 5th International, 2006, pp. 1-5.

[17] S.M. BLAIR, The Analysis and Application of Resistive Superconducting Fault Current Limiters in Present and Future Power Systems 2013.

[18] K. MÜLLER, Self-field hysteresis loss in periodically arranged superconducting strips. Physica C: Superconductivity 289(1), pp. 123-130. 1997.

[19] P. MANOHAR and W. AHMED, Superconducting fault current limiter to mitigate the effect of DC line fault in VSC-HVDC system. Presented at Power, Signals, Controls and Computation (EPSCICON), 2012 International Conference on. 2012, .

[20] H. KRAEMER, W. SCHMIDT, B. UTZ, B. WACKER, H. NEUMUELLER, G. AHLF and R. HARTIG, Test of a $1 \mathrm{kA}$ superconducting fault current limiter for DC applications. Applied Superconductivity, IEEE Transactions on 15(2), pp. 1986-1989. 2005.

[21] Y. MORISHITA, T. KOYAMA, I. YAMAGUCHI, S. OKABE, G. UETA and S. YANABU, «Development of dc-current-limiting circuit-breaker with superconducting fault current limiter», in Gas Discharges and their Applications, 2008. GD 2008. 17th International Conference on, 2008, pp. 97-100.

[22] X. PEI, S. SANDY SMITH and M. BARNES, «Superconducting Fault Current Limiters for HVDC Systems», Engineering and Physical Science Research Council; University of Manchester, 2015.

[23] W. CHEN et al., «System study of fault current limiter for shipboard power system,« in 2009 IEEE Electric Ship Technologies Symposium, 2009, pp. 376-379.

[24] T. YAZAWA, E. YONEDA, J. MATSUZAKI, M. SHIMADA, T. KURIYAMA, T.I. YAZAWA, T. OHKUMA, Y. SATO and Y. TAKAHASHI, Design and test results of $6.6 \mathrm{kV}$ high-tc superconducting fault current limiter. Applied Superconductivity, IEEE Transactions on 11(1), pp. 2511-2514. 2001.

[25] M. AHN et al., «The short-circuit characteristics of a DC reactor type superconducting fault current limiter with fault detection and signal control of the power converter, « Applied Superconductivity, IEEE Transactions on, vol. 15, pp. 2102-2105, 2005.

[26] D. HUI et al., Development and test of $10.5 \mathrm{kV} / 1.5 \mathrm{kA}$ HTS fault current limiter. Applied Superconductivity, IEEE Transactions on 16(2), pp. 687690. 2006.

[27] E. LEUNG et al., High temperature superconducting fault current limiter development. Applied Superconductivity, IEEE Transactions on 7(2), pp.985988. 1997.

[28] E. LEUNG, B. BURLEY, N. CHITWOOD, H. GUROL, G. MIYATA, D. MORRIS, L. NGYUEN, B. O'HEA, D. PAGANINI and S. PIDCOE, Design and development of a $15 \mathrm{kV}, 20 \mathrm{kA}$ HTS fault current limiter. Applied Superconductivity, IEEE Transactions on 10(1), pp. 832-835. 2000. 
[29] B. RAJU, K. PARTON and T. BARTRAM. A current limiting device using superconducting dc bias applications and prospects. Power Apparatus and Systems, IEEE Transactions on (9), pp. 3173-3177. 1982.

[30] V. ROZENSHTEIN, A. FRIEDMAN, Y. WOLFUS, F. KOPANSKY, E. PEREL, Y. YESHURUN, Z. BAR-HAIM, Z. RON, E. HAREL and N. PUNDAK, Saturated cores FCL-A new approach. Applied Superconductivity, IEEE Transactions on 17(2), pp. 1756-1759. 2007.

[31] CIGRE WG B4.57, «Guide for the Development of Models for HVDC Converters in a HVDC Grid,«pp. 221, 2014. 